\title{
An Exploration of Student Experiences with Learner-Centered Instructional Strategies
}

\author{
Jill E. Stefaniak \\ Old Dominion University, United States \\ Monica W. Tracey \\ Wayne State University, United States
}

\begin{abstract}
In this exploratory study, we examined how undergraduate students experience learning in a learner-centered teaching environment and their perceptions of motivation towards learning material in an introductory public speaking communications course. Six faculty members participated in a semester-long study where their teaching strategies were observed. Three faculty members participated in a cognitive apprenticeship where they were taught how to implement learner-centered instructional strategies into their coursework. Participants were 109 students who were enrolled in an introductory public speaking course. Data was collected by means of classroom observations, interviews, and the administration of a survey. Our findings indicated that students who were engaged in learner-centered activities within the communications course demonstrate higher levels of motivation towards the course and are more actively engaged in their learning.
\end{abstract}

Keywords: Learner-centered instruction; Instructional sequencing; Teaching strategies; Student motivation

\section{Introduction}

Instructors teaching at the undergraduate level are often challenged with selecting instructional strategies that meet their learners' needs but are feasible in terms of execution. Learning is an active process in which learners should be striving for permanent changes in their knowledge and behavior by utilizing information and resources around them (Mayer, 1982). Learner analyses often reveal similar demographic information, but as every instructor discovers, each student brings unique strengths and weaknesses to their learning environment. Customizing and sequencing instruction to meet both the individual needs of students and the group at large can sometimes be a daunting task for an instructor.

Keller (2012) defines motivation as a "person's desire to pursue a goal or perform a task, which is manifested by choice of goals and effort in pursuing the goal" (p. 85). With regard to designing instruction, it is important that instructional designers take a broader approach to the learning environment by not limiting their focus to the instructional content at hand. Keller (2012) suggests 
that consideration of all constructs that may influence human performance be factored into the design of instruction. These constructs include expectancy (Robbins et al., 2004), value (Eccles \& Wigfield, 2002), and achievement (Pintrich, 2000; Zimmerman, 2008).

Kacin (2013) contends that it is the responsibility of the instructional designer to integrate motivational strategies within instruction to help learners achieve their academic goals. A challenge facing our field is that due to discrepancies in the definitions of motivation and associated constructs, there is a paucity of empirical studies that have explored how to integrate motivational strategies into the instructional design process (Gabrielle, 2003; Keller, 1987; Main, 1993; Means, Jonassen, \& Dwyer, 1997; Moller, Huett, \& Holder, 2005).

Keller's (2010) ARCS model provides a framework for measuring learners' motivation across four components: attention, relevance, confidence, and satisfaction. Attention is comprised of gaining and keeping a learner's attention during instruction. Instructional strategies to assist with maintaining learners' attention include injecting personal and emotional material, increasing curiosity by asking questions, and sustaining interest with variations of human interest examples (Keller, 2010).

Relevance involves providing learners with instructional experiences to help them relate the instructional material to their everyday lives. Learners are more apt to be motivated to learn the content if they can find significance and relevance to what they are learning. It is important for the instructor to reiterate to their learners' the utility of the instructional material and how they can apply it in the real world. Providing statements of examples of the utility of instruction and providing concrete examples related to the learners' personal lives are examples of instructional strategies that promote relevance (Keller, 2010).

It is important for learners to be able to develop confidence while mastering a new skill. The confidence component in the ARCS model consists of learning requirements, success opportunities, and personal control (Keller, 2010). Expectations must be communicated to learners at the beginning of the lesson in order for students to understand the requirements needed for success. Instructional strategies are needed to enhance learners' beliefs in their competence by providing a variety of different learning experiences to increase their learning success. Personal control assists the learners' in recognizing when their success is based upon their efforts and abilities. Providing learners with frequent feedback can assist them with establishing a plan for a successful learning experience (Keller, 2010).

The final component to the ARCS model is satisfaction. It is important for there to be a reward at the end of the learning experience. Keller (2010) purports that satisfaction can be achieved through natural consequences where the learner is able to apply their newly acquired skill, positive consequences such as verbal praise or incentives to reward learner success and equity through the assurance of consistent measurement standards for learner accomplishments.

Learner-centered teaching strategies provide students with increased responsibility; promote critical thinking; support student development; and peer learning and teaching (McCombs \& Whistler, 1997). Strategies that involve collaboration with others, discovery learning, and solving authentic problems are all examples of learner-centered instructional strategies. These strategies 
that are focused on the learner and promote active learning can be integrated into an undergraduate learning environment. Instructors who have incorporated active learning and participatory activities within their instruction identified improvements amongst their students in conceptual understanding, test achievements, problem solving and student satisfaction (Pundak, Herscovitz, \& Shacham, 2010).

Learner-centered instruction should promote learning that results from interpretations of experience, active experiences that occurs in realistic and relevant environments and exposure to multiple perspectives (Richey, Klein \& Tracey, 2011). All three of these premises can be achieved through the use of face-to-face learning environments if coupled with learner-centered instruction. Jonassen, Howland, Moore, and Marra (2003) suggest that five factors are required to be present in order for learning to be considered meaningful. 1) Learning must be active where students have an opportunity to observe and manipulate the environment in which they are learning. 2) Constructivist learning opportunities must be provided to allow students to participate in realistic and relevant activities that promote collaborative learning with peers. 3) Learning must be goal directed where specific educational goals and outcomes are shared with students early in their experience. These goals serve as checkpoints for the instructor as well as the students to monitor progress throughout a course. 4) Authentic learning provides students with relevant experiences that they will be able to translate to real-world application. Case studies, an example of an authentic learning strategy, allow for students to practice problem-solving skills and are a means for instructors to determine whether students are mastering subject content. 5) Jonassen et al. (2003) also suggests that it is necessary for learners to be presented with opportunities for cooperative learning. These types of activities provide collaborative learning experiences where students can work amongst their peers and build upon their prior knowledge by engaging in conversations and relationships.

Traditional learning strategies in classrooms have typically consisted of learners being required to assume a passive learning role where the instructor spends the majority of class time lecturing and presenting course material. Learners are expected to come to class prepared, having read the textbook and additional assigned reading materials prior to class, and take lecture notes during the class. Common assessment techniques used with this more traditional approach include demonstrating one's competency by being administered an exam or test (Doyle, 2008).

Learner-centered instructional strategies promote increased responsibility amongst students in regards to their learning, support student development through the use of a variety of activities, provide students with opportunities to solve authentic problems, and promote critical thinking by participating in activities at both individual and group levels. Learner-centered instruction presents activities to students that require them to take a more active role in their own learning through self-teaching, collaboration with others, reflective practice, and problem-solving (Doyle, 2008). Instructional strategies need to be selected that can help achieve the aforementioned principles of instructional design. Referring to the premises of constructivist learning theory and the first principles of instructional design, instructors can carefully select media that help the learner apply new material, work in a collaborative learning environment and engage in active learning.

Public speaking courses have become a requirement for many undergraduate programs across the United States. While empirical studies have been conducted examining instructional strategies 
used in these courses, there is a paucity of research that has identified best practices for the incorporation of learner-centered instruction. Another limitation to the existing literature is that studies focused on pedagogical practices in public speaking courses are limited to individual assignments. Keith and Lundberg (20141) suggest that "public speaking might be best conceptualized as a course dedicated to clear communication; or in the social science-informed tradition and compelling personal and professional interactions" (p. 141). They contend that the tradition discourse used for teaching public speaking needs to refocus to include a pedagogical approach that is more humanistic and focuses on interacting with an audience.

A challenge that many universities face is the large number of public speaking course sections that are offered each semester (Hendrix, 2000; Sawyer \& Behnke, 2001). In an effort to standardize assignments and overall course expectations, there is a push to avoid learner-centered approaches to instruction and create a one-size-fits-all curriculum. The few studies that have been published exploring the use of more learner-centered instructional techniques in public speaking courses have focused on student audiences comprised of English and a second language students as students with disabilities (Hendrix, 2000; Sawyer \& Behnke, 2001). These learner-centered have only been applied to a small group of students who have demonstrated the need for additional guidance throughout the course of a semester.

There have been studies in communication education that have looked at the incorporation of individual learner-centered strategies. Levasseur, Dean, and Pfaff (2004) conducted interviews with several public speaking instructors to identify what instructional strategies have been found to be most useful for students. Feedback from 23 college instructors revealed that in order to yield optimal performance, students must be provided with frequent feedback, multiple examples, modeling, and opportunities for practice. Their study also suggested that further research was needed to explore the relationship between instructional sequencing and student performance outcomes in the realm of public speaking.

In an effort to demonstrate the relevance of public speaking, Weintraub (1999) incorporated a service-learning activity into coursework to provide students with an opportunity to hone their public speaking skills in their community. Students were tasked with visiting local non-profit organizations in their community and making presentations on a variety of topics. This provided them with an opportunity to gain experience presenting to different audiences as well as serving a community need. Not only were students able to enhance their public speaking schools beyond the classroom, they experienced the need for customizing presentations and speech outlines for a specific audience.

The incorporation of service-learning activities into public speaking coursework allows for the instructor to bridge theory to practice and provide opportunities to apply what they are learning in a real-life context. While this approach may be considered more learner-centered, Weintraub (1999) notes challenges instructors must be cognizant of during the assignment. Logistical challenges may arise during the planning of such activities and scheduling organizations within the constraints of any given semester. There are also challenges with ensuring that students will be responsible and fulfill the assignment requirements in the community. Instructors may experience challenges with grading the experiences depending on the number of students in the course. There may be issues around fair grading if students are visiting different non-profit organizations 
and may be asked to deliver different presentations. While these types of activities are beneficial to a student's development, the instructor must be prepared to undergo a significant amount of planning prior to the course.

Mackenzie (2007) incorporated the use of film clips to generate discussion among aspiring teachers who were enrolled in a public speaking course to enhance their teaching skills. The students reviewed several video clips during class of various teachers and asked to critique their teaching style and public speaking skills. Afterwards, the students were encouraged to discuss in groups their findings. A second part of the assignment was for the students to identify and observe a public speaker in their community and report back a critique based on their observations. The use of film was used to follow other studies conducted in communication courses that included film to provide clarification to class concepts (Bunz, 2006; Proctor 2000).

Chou (2011) explored whether learner-centered instructional activities that were focused on memory recall would be a viable instructional strategy for assisting students with speech delivery. Chou's findings revealed that retrieval strategies assisted students with memorizing information and better equipped them to engage in conversations with their audience members without losing pace during a speech. Dallimore, Hertenstein, and Platt (2008) studied the implications classroom discussions can have on students' oral and written communication skills. Their pilot study revealed that students felt more comfortable delivering speeches when they had an opportunity to engage in informal discussions during class. The increased classroom participation enabled students to practice their oral communication skills on a more consistent basis. In summary, the field of communication education could benefit from further exploration into the viability of learnercentered instructional strategies in undergraduate classroom environments.

\section{Purpose of the Study}

The purpose of this study was to determine how undergraduate students experience learnercentered instructional strategies in a public speaking course. Faculty participants participated in a cognitive apprenticeship where they worked with an instructional designer to incorporate learnercentered instructional strategies in their courses as a means to increase students' levels of motivation regarding course material. This study applied principles of ethnography to explore the influence that learner-centered instructional strategies had on student motivation in an undergraduate public speaking course. Customized instructional activities were employed to meet the needs of individual faculty participants through the duration of their course. The intent of this study was to examine the types of instructional strategies that were commonly implemented in an undergraduate public speaking learning environment and explore whether learner-centered instructional strategies could improve students' motivation regarding course concepts. This article provides the results of comparing students' perceptions of motivation related to instructional strategies used in a public speaking classroom.

We sought to explore the following research questions:

Question 1: How do undergraduate students experience learning in a learner-centered teaching environment? 
Question 2: What is the difference in perception of motivation, if any, between students enrolled in a course employing learner-centered instructional strategies, as compared to one that is not?

\section{Methodology}

\section{Setting}

This study took place in six sections of a freshman-level introductory public speaking course at a public university in a metropolitan area. The course is designed to fulfill a general education oral competency and is required of all undergraduate students. Key objectives of the course include providing students with a basic understanding of communication theory, the fundamentals of delivering a speech, and opportunities to practice public speaking skills. Methods of assessment and course textbooks for the introductory course have been standardized across all sections. Instructors are allowed to decide individually the order of instruction, assignment due dates, and classroom activities that take place throughout the semester.

\section{Participants}

The study population consisted of six faculty members ( 3 men, 3 women) who were responsible for teaching an undergraduate introductory public speaking course. Faculty participants' experience with teaching the introductory public speaking course ranged from two semesters to more than 20 semesters. Inclusion and exclusion criteria required that the faculty participants were to teach a face-to-face section of the public speaking course and could not possess an advanced degree in instructional design. Faculty participants volunteered to participate in the semester-long study and were randomly assigned to either a control group or an experimental group. Faculty participants enrolled in the experimental group participated in a semester-long cognitive apprenticeship where they worked with the primary researcher, an instructional designer, to incorporate learner-centered instructional strategies in their courses. Table 1 provides an overview of the faculty participants' demographics.

Table 1. Faculty Participants' Demographics

\begin{tabular}{|c|c|c|c|c|c|}
\hline Group & Participant & Gender & Age Range & $\begin{array}{c}\text { Approximate Years of } \\
\text { Teaching Experience }\end{array}$ & $\begin{array}{c}\text { Approximate } \\
\text { Number of } \\
\text { Times They } \\
\text { Have Taught } \\
\text { Course }\end{array}$ \\
\hline \multirow{3}{*}{ Experimental } & EXP 1 & Female & $50-59$ & $10+$ & 11 \\
\cline { 2 - 6 } & EXP 2 & Male & $30-39$ & 4 & 4 \\
\cline { 2 - 6 } & EXP 3 & Female & $30-39$ & 7 & 17 \\
\hline \multirow{3}{*}{ Control } & CON 1 & Male & $30-39$ & 1 & 2 \\
\cline { 2 - 6 } & CON 2 & Female & $30-39$ & 10 & 6 \\
\cline { 2 - 6 } & CON 3 & Male & $50-59$ & 3 & 20 \\
\hline
\end{tabular}


Student participants for this study consisted of undergraduate students who were enrolled in one of the faculty participants' sections of the introductory public speaking course. A total of 162 students were enrolled in the six sections (27 students in each class section) that were included in the study. A total of 109 students participated in the study by completing a survey and 36 students participated in an interview at the end of the semester. Students who had been previously enrolled in the course or had failed the course during a previous semester were excluded from participating in the study.

\section{Procedures}

The study protocol was reviewed and approved by the university's Institutional Review Board for protection of human subjects in research. The study occurred during the course of a 15-week semester and consisted of participant-observation, open-ended interviews, and surveys. In order to ensure the reliability of corroborating results from the participant observations, surveys, and interviews, triangulation methods were used (Fetterman, 2010; Wolcott, 2008). Faculty participants were recruited and randomly assigned to control and experimental groups. Faculty participants assigned to an experimental group were provided with a variety of different learnercentered instructional strategies to employ within their classroom.

Utilizing a cognitive apprenticeship framework (Collins, Brown, \& Newman, 1989), the primary researcher, an instructional designer, worked with the experimental faculty participants on an individual basis to help them customize learner-centered instructional lesson plans. She worked very closely with the experimental faculty at the beginning of the semester and gradually faded support (Dennen \& Burner, 2007) so that they were able to select and implement learner-centered strategies on their own without assistance. The cognitive apprenticeship was designed to incorporate modeling, scaffolding, coaching, articulation, reflection, and exploration (Collins et al., 1989) in order to provide the experimental faculty participants with the necessary support to implement different instructional strategies during their class sessions.

The cognitive apprenticeship took place during a 15-week semester and was divided into three phases, each lasting five weeks. During Phase 1, we worked very closely with the experimental faculty enrolled in the cognitive apprenticeship group to coach them through how to design learner-centered instructional strategies that they could integrate into their coursework. Our intent was to provide a scaffolded approach to teaching them how to integrate more learnercentered activities into their coursework. We met with the instructors to discuss challenges they perceived and were experiencing teaching certain topics and worked to identify ways to engage their students. During these first five weeks, we created class activities for them to implement during class. Their only responsibility was to provide feedback on the activities prior to implementation so that modifications could be made when necessary prior to implementation.

Phase 2 consisted of the faculty participants developing their own instructional activities that were similar to those developed by us in Phase 1 . We provided them with feedback prior to the activities being implemented in their classrooms. Our goal for Phase 2 was for the faculty 
participants to be able to design activities on their own so that they'd be able to continue these activities upon completion of the study.

Phase 3 required the faculty participants to design activities on their own with no feedback. This was done in order to see if they were able to implement these activities on their own without any coaching or instructional support. This was also done due to the time limitations of the 15-week semester and our interest in exploring whether a cognitive apprenticeship could be implemented within a limited time frame. Additional details regarding the construction of the cognitive apprenticeship framework are laid out in greater detail in a larger study (Stefaniak, 2013).

The experimental faculty participants participated in two interviews at the beginning and end of the study, were observed during five observation sessions, completed three self-reflections pertaining to learner-centered instructional strategies they implemented, and completed a survey along with their students. Faculty participants enrolled in the control group were interviewed at the beginning of the study, observed five times throughout the semester, and administered a survey along with their students. The control group participants were not provided with any supportive instructional materials and were instructed to continue teaching and leading their class sessions the way they typically would. We did not provide any feedback regarding the instructional strategies at any point during the study because we did not want to influence the participants during the study. We also withheld feedback during the participant observation sessions.

\section{Instruments}

Participant observations. Faculty participants in both groups were observed on five different occasions for the purpose of "observing the activities, people, and physical aspects of the situation" (Spradley, 1980, p. 54). Faculty participants were not provided with confirmation of any dates in an attempt to alleviate the possibility that faculty might change their lesson plans based on knowledge that an observer would be present. The observation sessions provided insight as to the types of instructional activities being incorporated within the class and student engagement. During the observation sessions throughout the study, the role of the primary researcher was one of a moderate participant (Spradley, 1980). Ethnographic analysis methods consisting of domain analysis and thematic analysis were used.

Surveys. A survey designed to measure students' perceptions of motivation was administered to student participants enrolled in each faculty participant's class section. Students were administered surveys adapted from Keller's (2010) Course Interest Survey (CIS) and Instructional Materials Motivation Survey (IMMS). The surveys collected basic demographic information about the participant such as gender, age, and level of completion.

The CIS consisted of 34 items that were classified under four categories: attention, relevance, confidence, and satisfaction. The survey uses a five-point Likert-type scale ranging from (1) not true to (5) very true. Scores may range from a minimum of 34 to a maximum of 170 with a midpoint of 102 (Keller, 2010). The IMMS consisted of 36 items that were classified under the same four categories as the CIS. The survey also used a five-point Likert-type scale ranging from (1) not true to (5) very true. Scores may range from a minimum of 36 to a maximum of 180 with a 
midpoint of 108 (Keller, 2010). Surveys were administered to students in a manila envelope and students were instructed to complete the anonymous surveys and return them in the envelope. Students who chose not to participate were asked to hand in their incomplete surveys.

Scores were determined by "summing the responses for each of the four subscales (attention, relevance, confidence, and satisfaction) and the total score" (Keller, 2010, p. 284). In addition, overall scores of students' enrolled in the control group classes were compared to scores of students enrolled in the experimental group classes.

Interviews. In addition, semi-structured interviews were conducted with students enrolled in the faculty participants' classes at the end of the semester to obtain feedback regarding the instructional strategies that were employed during the course. We explained to students the purpose of the interviews during class and asked them to provide their contact information if they were interested. We agreed to interview all students that volunteered to be interviewed. All student interviews were recorded with a digital voice recorder and transcribed for qualitative analysis. Interview transcripts were analyzed for themes by listing each interview question in a separate column. A second researcher was brought in to review the interview transcripts and codes in order to verify whether or not the codes assigned were accurate.

\section{Results}

The first research question examined how students experienced learning in a class that places emphasis on learner-centered instruction. Through participant observations and interviews with students, it appeared that students were experiencing challenges with understanding the material in the textbook and being able to see a connection between course content and the public speaking assignments. Many also communicated that they were unable to see the relevance and need for a public speaking course as many were required to deliver individual and group presentations in other courses they were enrolled in. A total of 36 students participated in an interview at the end of the semester to share their perspectives of whether or not their instruction was learner-centered throughout the semester. Table 2 provides the distribution of students according to their year of enrollment in an undergraduate program.

Table 2. Distribution of Students Who Participated in an Interview According to Program Year

\begin{tabular}{|l|l|l|l|l|l|}
\hline & Freshman & Sophomore & Junior & Senior & Total \\
\hline CON 1 & 2 & 1 & 1 & 1 & 5 \\
\hline CON 2 & 2 & 6 & 3 & 2 & 13 \\
\hline CON 3 & 0 & 0 & 1 & 0 & 1 \\
\hline EXP 1 & 0 & 3 & 0 & 0 & 3 \\
\hline EXP 2 & 4 & 1 & 2 & 0 & 7 \\
\hline EXP 3 & 3 & 0 & 2 & 2 & 7 \\
\hline
\end{tabular}


Throughout the course of the semester, the primary researcher worked with the experimental faculty members to create and implement learner-centered instructional activities to engage their students. Advanced organizers were developed for the experimental faculty members to distribute to their students to assist the students with note taking and navigating through the textbook. The organizers were created for each chapter and included the same headings that were found throughout the readings. "Space was provided on the advanced organizer for students to write their own notes identify examples that were provided within the textbook, identify examples that were unique to them, and identify the main arguments within the reading" (Stefaniak, 2013, p. 221). The instructors were encouraged to incorporate questions into their lectures in order to make their presentations more interactive during the occasions when lecture was needed to communicate foundational information. During participant observations, it was observed that students were spending less time on their cell phones and working on other work when the instructor was walking around the room and frequently asking questions.

Group activities were integrated into every class session. Students were often divided into small groups and assigned a topic or a small portion of course materials that were to be covered during the class. They were tasked with reviewing the course materials, highlighting the key concepts, and teaching their peers about their assigned portion. Students were often tasked with developing their own examples to explain different theories and concepts that were mentioned in their textbook. This activity was done to provide relevance to the course material and help the students better understand the content.

Experimental faculty participants were also tasked with incorporating briefing and debriefing sessions into every class session. Briefing sessions consisted of the instructor going over a list of objectives for each class session as a means to provide students with a preview of what they could expect. During the briefing sessions, instructors highlighted course concepts from previous class sessions to help the students make connections between the course materials. Debriefing sessions were conducted at the end of every class session as a means for the instructor to review with the students the progress they had made during the class as well as to preview or remind students of what they were responsible for preparing for the subsequent class session.

Reflective practice was incorporated into the classroom by providing students with opportunities to reflect on activities at the end of class sessions. Examples of reflective exercises included asking students to write one new thing that they had learned during a class session or writing how they would incorporate the material covered during a particular class session into an upcoming assignment.

Students confirmed the findings from the classroom observations during the student interviews. Many found the group activities to be helpful with better understanding the material and they found the advanced organizers to be of great assistance with navigating through the textbook and making their own study notes. The following are examples of student feedback regarding the instructional strategies used during the study: 
Control Group:

- "We had a guest speaker last [week] and I learned more in his forty minute lecture than I have the entire semester because he was very engaging and had really good real life examples and broke everything down. He kind of kept asking us how we felt instead of just telling us."

- "To be honest, I wish he'd do more. Like right now you just asked me if there are any activities. There's none."

Experimental Group:

- "She brings examples and like the way she explains things really sophisticated and she breaks it down, I think it's sentence by sentence, and everybody understands and we are all just like oh that's what the books talking about." - Student referring to activities that EXPF3 incorporates within the classroom.

- "She engages with us. She uses the classroom activities to keep us involved and I think if she didn't do the activities, then it would be boring without them."

- "Yeah, a lot of examples, she uses a lot of examples. Like I said, the book is really hard to understand. She made it easier using a lot of examples, not from the book, but she is like real life related examples."

The second research question sought to explore whether a difference in perception of motivation would exist between students enrolled in a course employing learner-centered instructional strategies, as compared to a course that is not. A total of 109 students participated in the surveys. Participants in the control group ( $N=53,26$ male and 27 female) ranged from 17 to 40 years of age $(M=20.8, S D=4.2)$. Participants in the experimental group ( $N=56,26$ male and 30 female) ranged from 18 to 61 years of age $(M=21.6, S D=6.2)$. Tables 3 and 4 provide the distribution of students according to their year of enrollment in an undergraduate program and the results of the results of the Course Interest Survey (Keller, 2010) for both the experimental groups and the control groups. The overall distribution of the ARCS score and well as each sub score for attention, relevance, confidence, and satisfaction are provided.

Table 3. Distribution of Students Who Completed the Survey According to Program Year

\begin{tabular}{|l|l|l|l|l|l|l|}
\hline & Freshman & Sophomore & Junior & Senior & Undisclosed & Total \\
\hline CON 1 & 7 & 3 & 3 & 3 & 1 & 17 \\
\hline CON 2 & 4 & 10 & 3 & 2 & 0 & 19 \\
\hline CON 3 & 9 & 3 & 5 & 0 & 0 & 17 \\
\hline EXP 1 & 4 & 9 & 3 & 2 & 0 & 18 \\
\hline EXP 2 & 8 & 5 & 4 & 0 & 0 & 17 \\
\hline EXP 3 & 5 & 6 & 3 & 7 & 0 & 21 \\
\hline
\end{tabular}


Table 4. Distribution of Student Scores in Relation to the Course Interest Survey

\begin{tabular}{|c|c|c|c|c|c|c|}
\hline Group & $\mathbf{N}$ & Score & Mean & $\begin{array}{l}\text { Standard } \\
\text { Deviation }\end{array}$ & Minimum & Maximum \\
\hline Control & 53 & Overall ARCS & 130.6 & 21.2 & 87.0 & 162.0 \\
\hline \multirow[t]{4}{*}{ Groups } & & Attention & 25.4 & 7.3 & 10.0 & 37.0 \\
\hline & & Relevance & 35.6 & 6.0 & 22.0 & 45.0 \\
\hline & & Confidence & 34.3 & 4.4 & 17.0 & 40.0 \\
\hline & & Satisfaction & 35.2 & 6.9 & 17.0 & 45.0 \\
\hline Experimental & 56 & Overall ARCS & 139.3 & 17.9 & 87.0 & 166.0 \\
\hline \multirow[t]{4}{*}{ Groups } & & Attention & 28.7 & 6.2 & 16.0 & 39.0 \\
\hline & & Relevance & 38.4 & 6.0 & 21.0 & 45.0 \\
\hline & & Confidence & 35.2 & 3.7 & 20.0 & 40.0 \\
\hline & & Satisfaction & 37.0 & 5.3 & 21.0 & 45.0 \\
\hline
\end{tabular}

A two-tailed t-test was done to determine a difference between the control groups and experimental groups in terms of their overall ARCS score. The results of test revealed statistical significance $(t(\alpha=0.05,107)=2.33$ with a $p$-value $=0.0218)$ that students in the experimental groups achieved higher overall ARCS scores than students in the control groups. A two-tailed t-test to explore the overall difference pertaining to students attention scores generated statistically significant results $(t(\alpha=0.05,107)=2.55$ with a $p-$ value $=0.0123)$. A paired t-test to explore the difference between the control and experimental groups relevance scores revealed a statistically significant difference $t(\alpha=0.05,107)=2.38$ with a $p$-value $=0.0191$. Paired t-tests did not reveal significant variation in students' confidence or satisfaction scores; however, students in the experimental and control groups demonstrated a uniformly high level of confidence.

Actual empirical testing utilizing the Multiple Comparison Tukey HSD Test (Table 5) found several significant differences.

Table 5. Results of Multiple Comparison Tukey HSD Test for Overall ARCS Score

\begin{tabular}{|l|l|l|}
\hline Assigned Faculty Comparison & Difference Between Means & p-Value \\
\hline EXP2- EXP1 & 17.6 & 0.0104 \\
\hline EXP2- CON2 & 20.5 & 0.0015 \\
\hline EXP2-CON1 & 26.8 & 0.0002 \\
\hline CON3-CON2 & 19.5 & 0.0017 \\
\hline CON3-CON1 & 25.7 & 0.0002 \\
\hline EXP3-CON1 & 21.2 & 0.0150 \\
\hline
\end{tabular}


In regard to the ARCS Score students in experimental group 2 have statistically significant higher scores when compared to the students in control groups 1 and 2 and experimental group 1 . This suggests that experimental group 2 students show more interest in the course toward EXP2 than respective students show with CON1, CON2, and EXP1. Additionally the ARCS Scores for students in control group 3 are statistically significant higher than the ARCS Scores from students in control groups 1 and 2, which is suggestive that students in control group 3 showed more interest in the course toward assigned CON3 more so than students in control groups 1 and 2. Finally, students in experimental group 3 had statistically significant higher ARCS scores than students in control group 1. It is suggested that students in experimental group 3 showed more interest in the course toward EXP3 than students in control group 1 showed toward CON 1.

Table 6 contains the distribution of the results of the Instructional Materials Motivation survey (Keller, 2010) for both the experimental groups and the control groups. The overall distribution of the ARCS score and well as each sub score for attention, relevance, confidence, and satisfaction are provided.

Table 6. Distribution of Student Scores in Relation to the Instructional Materials Motivation Survey

\begin{tabular}{|c|c|c|c|c|c|c|}
\hline Group & $\mathbf{N}$ & Score & Mean & $\begin{array}{l}\text { Standard } \\
\text { Deviation }\end{array}$ & Minimum & Maximum \\
\hline Control & 53 & Overall ARCS & 125.3 & 22.0 & 65.0 & 177.0 \\
\hline \multirow[t]{4}{*}{ Groups } & & Attention & 37.4 & 8.7 & 19.0 & 58.0 \\
\hline & & Relevance & 32.3 & 6.3 & 18.0 & 45.0 \\
\hline & & Confidence & 34.6 & 5.2 & 20.0 & 44.0 \\
\hline & & Satisfaction & 21.0 & 5.5 & 7.0 & 30.0 \\
\hline Experimental & 56 & Overall ARCS & 134.6 & 24.6 & 45.0 & 174.0 \\
\hline \multirow[t]{4}{*}{ Groups } & & Attention & 39.5 & 10.3 & 11.0 & 58.0 \\
\hline & & Relevance & 36.2 & 6.2 & 15.0 & 45.0 \\
\hline & & Confidence & 35.8 & 5.6 & 13.0 & 45.0 \\
\hline & & Satisfaction & 23.1 & 5.2 & 6.0 & 30.0 \\
\hline
\end{tabular}

A two-tailed t-test to determine whether there was a difference between the control groups and experimental groups for their overall ARCS score revealed statistical significance $t(\alpha=0.05,107)=2.08$ with a $p$-value $=0.0402$. A paired t-test revealed statistical significance that favored students' in the experimental groups' responses $t(\alpha=0.05,107)=3.29$ with a $p$-value $=0.0014$ in terms of relevance. Similarly, a paired t-test to measure the difference regarding satisfaction revealed statistical significance $t(\alpha=0.05,107)=2.09$ with a $p-$ value $=0.0390$. Paired t-tests did not reveal significant variation in students' attention scores or confidence scores; however, the control groups and experimental groups demonstrated uniformly high confidence scores much like their confidence scores in the Course Interest survey. Actual empirical testing utilizing the Multiple Comparison Tukey HSD Test (Table 7) and found several significant differences. 
Table 7. Results of Multiple Comparison Tukey HSD Test for Overall ARCS Score

\begin{tabular}{|l|l|l|}
\hline Assigned Faculty Comparison & Difference Between Means & p-Value \\
\hline EXP2-CON1 & 24.5 & 0.0247 \\
\hline EXP2-CON2 & 24.9 & 0.0034 \\
\hline CON3-CON2 & 19.9 & 0.0190 \\
\hline
\end{tabular}

In regard to the ARCS Score students within experimental group 2 have statistically significant higher scores when compared to the students in control groups 1 and 2 . This suggests that experimental group 2 students' view the instructional materials more favorably from EXP2 than respective students do with CON1 and CON2. Additionally the ARCS Scores for students in control group 3 are statistically significant higher than the ARCS Scores from students in control group 2, which is suggestive that students in control group 3 view the instructional materials more favorably from CON3 more so than students in control group 2 do with CON2.

\section{Conclusion}

The purpose of this study was to utilize an ethnographic approach to explore how students in a public speaking course experienced learning in a learner-centered teaching environment and whether that yielded a difference in terms of their perception of motivation for learning course content. The results of this study suggest that students benefit from learning in a learnercentered teaching environment particularly when relevance of learning activities can be justified. The following themes emerged through participant observation, student interviews, and student surveys.

\section{Student Preparation}

Many students admitted to coming to class unprepared on non-speech days. The lack of preparedness was consistent among all classes regardless of being assigned to the control or experimental groups. This posed challenges for instructors in the experimental groups who were responsible for implementing more learner-centered strategies during their class sessions. The use of the advanced organizers provided a solution for the faculty participant and their students by providing students with a tool to assist them with organizing the content they were responsible for learning in the textbook as well as ensuring that students were being provided with the necessary foundational information needed to participate in classroom activities and discussions. Students took a more active participatory role in their synthesizing their notes by having to look through course materials on their own and complete the questions, tables, and definitions that were often included in the advanced organizer. 


\section{Instructional Strategies}

Students in the experimental groups reported higher levels of satisfaction with course content and higher scores in terms of relevance of the material. The instructional activities that were implemented within the experimental class sessions provided students with increased opportunities to interact, engage, and view the course materials that they were responsible for, further supporting the tenets of constructivism (Richey et al., 2011). Active class discussions and group activities not only increased student participation during class, it also provided them with additional opportunities to practice and improve upon their oral and written communication skills.

Students in the control group expressed that they wished they had more opportunities to go over materials in the textbook with their instructor rather than sitting through class sessions that consisted solely of lecture. It was documented during the classroom observation sessions that faculty participants in the experimental group engaged in more class discussions, interactive lectures where they posed questions to their students, and opportunities to discuss pertinent examples from multiple perspectives as compared to faculty participants in the control group. It can be speculated that the increase in activities and additional examples helped students see the relevance of a public speaking course to their academic, professional, and personal lives.

\section{Implications}

This study poses two implications for instructional design in higher education. The first implication includes the necessity for instructors to assist students with understanding relevance of course content. Students were more apt to participate in activities during class if they understood how it would contribute to their professional development. The experimental faculty participants' students reported higher ratings in terms of course interest as well as motivation to complete the course activities. In order to assist students with making long lasting connections with course material and developing a permanent understanding, instructors must provide students with a multitude of examples that can be applied in a realistic context (Duncan, 1996; Richey et al, 2011). Learner-centered instruction provides the opportunity for students to develop a stronger rapport with the instructor and have more meaningful conversations that can be built upon throughout the course of instruction. The feedback provided by student interviews and surveys further supports Kahl and Venette's (2010) recommendation that instructors in higher education shift their teaching focus to a more decentralized model that places greater responsibility and involvement of the student.

The second implication includes how instructional sequencing is factored into learner-centered instruction. Building off of the recommendations made by Levasseur et al. (2004) to further explore the relationship between instructional sequencing and student performance outcomes, emphasis was placed on providing more structured instructional sequencing through the incorporation of briefing and debriefing sessions during each class session. The incorporation of briefings and debriefings provided a consistent structure for instructional delivery and assisted students with building off of prior knowledge from previous class sessions. The constant repetition and rehearsal throughout the semester supported Chou's (2011) findings that learner-centered activities and regular discussion yielded improved levels of students' confidence and satisfaction in 
relation to course content. Future research is warranted on the types of learner-centered instructional strategies that can be implemented in an undergraduate classroom as well the frequency with which they are used.

In summary, this study was successful in exploring how learner-centered instruction could be integrated into an undergraduate public speaking course. Results from both quantitative and qualitative data collection methods suggest that students are more apt to see the relevance with the course material being presented as well as higher levels of satisfaction towards learning when they are provided the opportunity to engage in learner-centered instruction.

\section{References}

Bunz, U. (2006). Reviewing organizational communication concepts with the movie "office space". Communication Teacher, 20(2), 36-39.

Chou, M. (2011). The influence of learner strategies on oral presentations: A comparison between group and individual performance. English for Specific Purposes, 30, 272-285.

Collins, A., Brown, J.S., \& Newman, S.E. (1989). Cognitive apprenticeship: Teaching the craft of reading, writing, and mathematics. In L.B. Resnick (Ed.). Knowing, learning, and instruction: Essays in honor of Robert Glaser (pp. 453-494). Hillsdale, NJ: Lawrence Erlbaum Associates.

Dallimore, E.J. Hertenstein, J.H., \& Platt, M.B. (2008). Using discussion pedagogy to enhance oral and written communication skills. College Teaching, 56, 163-172.

Dennen, V.P. \& Burner, K.J. (2007). The cognitive apprenticeship model in educational practice. In J.M. Spector, M.D. Merrill, J. van Merrienboer \& M.P. Driscoll (Eds.), Handbook of research for educational communications and technology (pp. 425-439). New York: NY: Taylor \& Francis Group.

Design-Based Research Collective. (2003). Design-based research: An emerging paradigm for educational inquiry. Educational Researcher, 32(1), 5-8.

Doyle, T. (2008). Helping students learn in a learner-centered environment: A guide to facilitating learning in higher education. Sterling, VA: Stylus.

Duncan, S.L.S. (1996). Cognitive apprenticeship in classroom instruction: Implications for instructional and technical teacher education. Journal of Instructional Teacher Education, 33(3), 66-86.

Eccles, J.S. \& Wigfield, A. (2002). Motivational beliefs, values, and goals. Annual Review of Psychology, 53, 109-132.

Fetterman, D.M. (2010). Ethnography: Step-by-step. ( $3^{\text {rd }}$ ed.). Los Angeles, CA: Sage.

Gabrielle, D. M. (2003). The effects of technology-mediated instructional strategies on motivation, performance, and self-directed learning (Unpublished doctoral dissertation). Florida State University, Tallahassee.

Hendrix, K.G. (2000). The teaching assistant's guide to the basic course. Belmont, CA: Wadsworth. 
Jonassen, D.H., Howland, J., Moore, J., \& Marra, R.M. (2003). Learning to solve problems with technology. Upper Saddle River, NJ: Merrill-Prentice Hall.

Kacin, S.E. (2013). A design- based research study examining the impact of motivational emailed messages to first year students (Unpublished doctoral dissertation). Wayne State University, Detroit.

Kahl, H. \& Venette, S. (2010). To lecture or let go: A comparative analysis of student speech outlines from teacher-centered and learner-centered classrooms. Communication Teacher, 24(3), 178-186.

Keith, W. \& Lundberg, C. (2014). Creating a history for public speaking instruction. Rhetoric \& Public Affairs, 17(1), 139-146.

Keller, J. M. (1987). Strategies for stimulating the motivation to learn. Performance and Instruction, 28(8), 1-7.

Keller, J.M. (2010). Motivational design for learning and performance. New York, NY: Springer.

Keller, J.M. \& Deimann, M. (2012). Motivation, volition, and performance. In R.A. Reiser \& J.V. Dempsey (Eds.), Trends and issues in instructional design and technology ( $3^{\text {rd }}$ Ed.) (pp. 8495). Boston, MA: Pearson.

Levasseur, D.G., Dean, K.W., \& Pfaff, J. (2004). Speech pedagogy beyond the basics: A study of instructional methods in the advanced public speaking course. Communication Education, 53(3), 234-252.

Mackenzie, L. (2007). "Double duty": A suggested activity for meeting the challenge of teaching and performing the freshman public speaking course. Communication Teacher, 21(1), 12-15.

Main, R.G. (1993). Integrating motivation into the instructional design process. Educational Technology, 33(12), 37-41.

Mayer, R.E. (1982). Learning. In H. Mitzel (Ed.), Encyclopedia of educational research (pp. 10401058). New York, NY: The Free Press.

McCombs, B. \& Whistler, S. (1997). The learner-centered classroom and school. San Francisco, CA: Jossey Bass.

Means, T. B., Jonassen, D. H., \& Dwyer, F. M. (1997). Enhancing relevance: Embedded ARCS strategies vs. purpose. Educational Technology Research and Development, 45(1), 5-17.

Merrill, M.D. (2002). First principles of instruction. ETR\&D, 50(3), 43-59.

Moller, L., Huett, J., Holder, D.(2005). Examining the impact of motivation on learning communities. Quarterly Review of Distance Education, 6(2), 137-143.

Pintrich, P.R. (2000). An achievement goal theory perspective on issues in motivation terminology, theory, and research. Contemporary Educational Psychology, 25(1), 92-104.

Proctor, R.F. (2000). Using "swing kids" to teach theories of persuasion. Communication Teacher, 14(2), 5-6. 
Pundak, D., Herscovitz, O., \& Shacham, M. (2010). Attitudes of face-to-face and e-learning instructors towards active learning. European Journal of Open, Distance, and E-Learning, 112.

Richey, R.C., Klein, J.D., \& Tracey, M.W. (2011). The instructional design knowledge base: Theory, research, and practice. New York, NY: Routledge.

Robbins, S.B., Lauver, K., Le, H., Davis, D., Langley, R., \& Carlstrom, A. (2004). Do psychological and study skill factors predict college outcomes? A meta-analysis. Psychological Bulletin, 130(2), 261-288.

Sawyer, C.R. \& Behnke, R.R. (2001). Computer-assisted evaluation of speech competencies in the basic speech course. Journal of the Association for Communication Administration, 30(3), 104-110.

Spradley, J.P. (1980). Participant observation. New York, NY: Holt, Rinehart and Winston.

Stefaniak, J.E. (2013). The use of cognitive apprenticeships to teach learner-centered instructional strategies in an undergraduate learning environment (Unpublished doctoral dissertation). Wayne State University, Detroit.

Weintraub, S. (1999). Giving students "all of the above": Combining service-learning with the public speaking course. Voices of strong democracy: Concepts and models for servicelearning in communication studies (pp. 119-124). Sterling, VA: American Association for Higher Education.

Wolcott, H.F. (2008). Ethnography: A way of seeing. ( $2^{\text {nd }}$ ed.). New York, NY: Alta Mira Press.

Zimmerman, B.J. (2008). Investigating self-regulation and motivation: Historical background, methodological developments, and future prospects. American Education Research Journal, 45(1), 166-183.

Correspondence: Jill E. Stefaniak, Assistant Professor, Instructional Design and Technology, Department of STEM Education and Professional Studies, Darden College of Education, Old Dominion University, Norfolk, Virginia, United States. 